El Modelo de Desarrollo Argentino (MDA)

\title{
Una forma de hacer posible/visible otro modelo de Desarrollo
}

Paula Meschini

Licenciada en Servicio Social (UNMDP)

Docente-investigadora (UNMDP)

E-mail: paulameschini@gmail.com 
Resumen

El ingreso de América Latina en este tercer milenio implicó hacer frente a un mundo, caracterizado por una poli hegemonía, por el capitalismo financiero transnacional, por un sistema científico tecnológico monopolizado por las grandes corporaciones en medio de un fuerte proceso de pauperización y exclusión social. Cabe entonces, interpelarnos acerca de la posibilidad de habilitar zonas de refugio que presenten alternativas para hacer frente al neoliberalismo. En este sentido, se sostiene que la asunción del Pte. Néstor Kirchner (2003), abrió un intersticio que permitió el establecimiento de las bases políticas, macroeconómicas y jurídicas para el establecimiento de relaciones diferentes entre la sociedad, el mercado y el Estado viabilizando el surgimiento del Modelo de Desarrollo Argentino (MDA). La reducción de la pobreza, la recuperación del salario y del trabajo digno (OIT), en el marco de los convenios colectivos de trabajo, constan entre algunos de los muchos logros del MDA, que, sin embargo, expone aún cuestiones no resueltas propias de una sociedad todavía desigual. El presente artículo propone pensar el MDA desde una perspectiva descolonial del desarrollo que convoque a la construcción de un espacio semánticodiscursivo para visibilizar e impulsar otras perspectivas de desarrollo, que permitan concebir y vivir la vida en diálogo con Nuestra América (J. Martí).

\section{Palabras clave}

Modelo - Desarrollo - Descolonial

- Problemas Sociales - Política

argentina - Transformación social

\section{Abstract}

Income of Latin America in this third millennium meant to deal with a world, characterized by much hegemony, by transnational financial capitalism, by a technological scientific system monopolized, by big corporations in the midst of a strong process of impoverishment and social exclusion. Fit then, ask us about the possibility of enabling shelter areas which are alternatives to deal with neoliberalism. In this sense, it is held that the assumption of Pte. Néstor Kirchner (2003), opened a gap that allowed the establishment of political, macroeconomic and legal bases for the establishment of different relationships between society, the market and the State enabling the emergence of the Model of Argentine Development (MDA). The reduction of poverty, the recovery of salary and decent work (ILO), in the framework of collective labour agreements, comprise some of the many achievements of the MDA, which, however, exposes yet unresolved issues of a still unequal society. This article proposes to think the MDA from a decolonial perspective of development that convened to the construction of a semantico-discursivo space to make visible and promote other prospects, which allow thinking and living life in dialogue with our America (J. Martí).

\section{Kew Words}

Developement model -

Descolonialism - Social problems

- Social transformation 


\section{Introducción}

El presente trabajo se enmarca dentro de los avances realizados en el ante proyecto de tesis doctoral titulado "Posicionamientos del Trabajo Social respecto del Modelo de Desarrollo Argentino", para el Doctorado en Trabajo Social de la Universidad Nacional de Rosario.

Frente a la envergadura de los cambios sociales que se están produciendo en las sociedades contemporáneas, las reflexiones que a continuación se presentan parten de reconocer la limitación conceptual en la que nos hallamos inmersos al enfrentar "efectos nunca vistos, que han vaciado de sentido muchos de los conceptos y categorías con los cuales se aprendía el mundo circundante" (Yannuzzi, 2007:1). Es así que pareciera que muchas de las categorías que veníamos utilizando en las ciencias sociales perdieron su contenido y sentido, su fuerza explicativa y fundamentalmente su capacidad de denuncia.

En esta fase del capitalismo transnacional, la categoría de Desarrollo forma parte de esas categorías, propias de las ciencias sociales, que debe ser abordada en búsqueda de otras conceptualizaciones que den cuenta de las transformaciones existentes.

Resulta necesario, entonces, reconocer por un lado, la tradición discursiva en la que se inscribe esta categoría en América Latina, las deudas pendientes en relación a su capacidad para instrumentar diferentes respuestas a los problemas sociales vigentes; así como los desafíos que hoy debe enfrentar a partir de la reactualización del debate en el "campo del desarrollo del sub desarrollo" (Nahon, Rodríguez Enriquez y Schorr, 2006:327).

Para comenzar a establecer algunas precisiones, diremos en principio que el desarrollo, en este trabajo, es entendido como "bienestar del conjunto social” (Madoery, 2013:19). Esta definición inscribe a la categoría en una interpretación política del desarrollo que permite alejarse de las posiciones reducidas y sesgadas que circunscriben la discusión conceptual a una cuestión semántica o de giros interpretativos o a problemas únicamente vinculados a la economía, al crecimiento de los mercados, al "progreso". Pensar, entonces, la categoría de desarrollo "como categoría política” (Madoery, 2012:59) posibili- 
ta debates acerca de cómo América Latina, y en este caso Argentina, ha logrado desde una praxis política descolonial conformar un pensamiento situado acerca del desarrollo.

El tratamiento académico de las contradicciones propias del campo del "desarrollo del sub desarrollo" (Nahon, Rodríguez Enriquez y Schorr, 2006), en torno al problema del desarrollo en los países periféricos, como es el caso de Argentina (Torrado, 2004), se efectúa a partir de una reflexión político social del modelo de desarrollo argentino enunciado por el Pte. Néstor Kirchner durante su gobierno (2003-2007).

En esta línea, este artículo pretende aportar al debate en el campo ${ }^{1}$ del "desarrollo del subdesarrollo" desde un Trabajo Social inscripto en las preocupaciones propias de las ciencias sociales en búsqueda de la articulación de diferentes reflexiones y síntesis que permitan enriquecer y profundizar, simultáneamente las múltiples dimensiones de la vida social ${ }^{2}$, posibilitando la convivencia de elementos objetivos y subjetivos, estructuras, acciones -individuales y colectivas-, todo ello en un devenir histórico y biográfico a la vez.

En este sentido, este aporte se presenta como una provocación a la reflexión, que nos aleje de la sensación de vivir en la contingencia de lo dado y nos permita re pensar nuestra sociedad, no sólo a partir de considerar cómo la construimos, cómo la estamos construyendo, sino por sobre todo cómo podemos transformarla.

1 Se entiende por campo al "sistema de relaciones socialmente constituido por los agentes sociales directamente vinculados con su quehacer, que determina las condiciones específicas de producción y circulación de sus productos... En su interior se genera un capital común por cuya apropiación luchan los grupos que en él intervienen: los que detentan el capital y los que aspiran a poseerlo. Estos grupos tiene intereses comunes, lenguaje, complicidad que subyace a todos los antagonismos, intervienen en la lucha apuntala la reproducción del juego al otorgarle valor al mismo. La posesión del capital brinda poder y autoridad a los que dominan el campo, quienes sostienen estrategias más conservadoras, mientras los que luchan por su posesión adoptan estrategias más subversivas” (González Saibene, 2000:31).

2 Partimos de la no existencia de un mundo "verdadero", pre-existente a los fenómenos, que operaría como el fundamento de toda explicación y desde el cual se presupondrían significaciones; sino de la existencia de distintas construcciones sociales de la realidad (Berger-Luckmann, 1974; Schutz-Luckmann, 1977). "Cada grupo co-construye en la experiencia vivida y compartida una idea de realidad, una idea de verdad, una idea de error y una idea de normalidad. Estas ideas orientan sus esquemas de acción, su modo de vivir su entorno" (Lahitte, 1989:87). El "mundo" es una idea del mundo y existen distintos mundos posibles en una misma realidad, como ideas de un mismo pensamiento interactuando en una pugna de poder, e implican diferentes representaciones e interpretaciones de lo real, guiadas por la voluntad de verdad. 


\section{I. ¿Desde dónde partimos?: la etapa abismal}

"Es importante no perder la perspectiva, recordar desde qué abismo venimos para valorar certeramente lo que diariamente vamos logrando. Hemos retomado con grandes esfuerzos la senda del crecimiento económico, a la vez que hemos logrado reducir de manera significativa los índices de desocupación, de pobreza y de indigencia; hemos revertido la tendencia al incremento de la desigualdad, mejorando la distribución del ingreso, no lo que nosotros quisiéramos pero que, indudablemente, paulatina y lentamente se va revirtiendo (extracto del discurso brindado por el ex-presidente Néstor Kirchner en la ceremonia de clausura de la $53^{\text {a }}$ Convención anual de la Cámara Argentina de la Construcción desarrollada el 22 de noviembre de 2005 en Capital Federal, Argentina).

El capitalismo transnacional, en lo que se ha denominado el ciclo neoliberal, ratificó el lugar que ocupa Argentina en la división internacional del trabajo, asignándole la responsabilidad de producir y proveer materias primas y bienes con escaso valor agregado a las industrias de los países centrales encargados de su manufactura y redistribución internacional. Este lugar, asignado internacionalmente y costosamente asumido por las grandes mayorías de nuestro pueblo, dificultó y obturó gran parte de los esfuerzos que se realizaron, a lo largo de la historia argentina, para salir del proceso de primarización de la economía. Los casi treinta años consecutivos de neoliberalismo en democracia utilizaron la flexibilización laboral como una de las principales herramientas para destejer el entramado de relaciones solidarias que se establecieron durante el ciclo de Bienestar Argentino (Torrado, 2004).

En este sentido, compartimos el diagnóstico que efectúa Susana Torrado (2004) acerca de lo que nos pasó a los argentinos con la sustitución vertiginosa del Estado de Bienestar por un Estado Subsidiario ${ }^{3}$ que no tuvo en cuenta el costo social que implicaba esa transición, ge-

3 La autora entiende al Estado Subsidiario (ES) como un tipo de Estado que actúa sólo donde el Mercado no llega o donde no hay mercado. 
nerando la emergencia abrupta de "un inusitado volumen de desocupados, sub ocupados, asalariados precarios, en negro, ocultos, cuenta propistas marginales: 'los excluidos', 'los desafiliados', primero de la ciudadanía social y pronto de la ciudadanía política” (Torrado, 2004:17).

En este contexto, Argentina se insertó en un mundo unipolar atravesado por las grandes transformaciones sociopolíticas y económicas en marcha dadas por la globalización y la liberalización económica, la expansión de la hegemonía cultural de occidente, la pérdida de importancia de los colectivos sociales y la mercantilización de las relaciones sociales. La instauración de un nuevo orden mundial que se inaugura, de manera simbólica, con la caída del Muro de Berlín, y la presencia de un Estado Subsidiario en Argentina (Torrado, 2004) permite el despliegue sin fronteras del neoliberalismo. Bourdieu lo advirtió en una entrevista realizada en la ciudad de Buenos Aires en 1998, donde afirmó que el neoliberalismo, en cumplimiento de su principal objetivo, era capaz de destruir todas las estructuras colectivas capaces de obstaculizar la lógica del libre mercado como son "la nación, los colectivos de defensa de los derechos de los trabajadores, la familia misma" (Bourdieu, 1998).

Es en este contexto que resulta de interés el análisis efectuado por Madoery, quien enfoca los treinta años de democracia argentina y sitúa al año 2001 como un punto de inflexión dentro del ciclo neoliberal (1975-2001) ${ }^{4}$ que inaugura la "etapa abismal”. La misma se caracterizó por constituir la fase final y crítica del proceso de desestructuración de las sociedades inaugurada en el ciclo neoliberal (Madoery, 2013) donde, como bien señala Bauman -en La globalización-, se inician diferentes procesos de des-territorialización que desvinculan, entre otras cuestiones, el capital y el trabajo, la creación y el mantenimiento de la riqueza, separando también a los viejos ricos de los pobres para acrecentar su riqueza para que "después de tanto

4 Este ciclo neo liberal “...comienza en 1975 con medidas de ajuste y persecución política, abarca la dictadura cívico militar y las primeras décadas de la transición democrática; contiene una etapa republicana (1983-1987), una etapa desreguladora y socialmente desintegradora (1987-2000) y una etapa abismal (2000-2002)" (Madoery, 2013:19). 
tiempo, el paraíso de la libertad total está al alcance de la mano" (Bauman, 2005:101).

Este "paraíso de la libertad total" existió en la Argentina neoliberal y pudo ser constatado empíricamente por Beccaria y Minujín, cuyas observaciones en el texto Desigualdad y exclusión. Desafíos para la política social argentina de fin de siglo, describen la magnitud de la polaridad y heterogeneidad inter-clase existente. Como evidencia el estudio, los ricos necesitaban cada vez menos de los pobres para sostener y/o aumentar sus riquezas. En esta etapa, los pobres en Argentina sólo constituían una preocupación estadística y no contaban con la protección del Estado de Bienestar (1945-1955) $)^{5}$ que implementó políticas sociales redistributivas del ingreso morigerando el conflicto social a partir de asegurar "beneficios para ambas partes a través de la acción mediadora del estado" (Beccaria y Minujín, 1993:32).

A pesar de los esfuerzos des-articuladores del neoliberalismo sobre la sociedad argentina, los restos del Estado de Bienestar, que aun subsistían compensando desigualdades generadas por el mercado en la puja distributiva durante esta "etapa abismal", fueron fuertemente atacados por los sectores neo-conservadores que haciendo uso de un lenguaje tecnocrático y supuestamente apolíticos señalaban la ineficiencia e ineficacia de las intervenciones estatales (altos costos, falta de transparencia, restricción a las libertades individuales y de mercado). Estos, entre otros argumentos, sirvieron para continuar socavando la universalidad de su presencia en la construcción y sostenimientos de sistemas públicos de protección social.

En un mundo globalizado, con un Estado Subsidiario, los pobres en Argentina se encontraron, entonces, con la novedad de que no contaban ya con la protección de los ricos, no contaban tampoco con la protección del Estado y, además, se había acabado el pleno empleo y había finalizado, también "la creencia de que el desempleo masivo

5 El Estado de Bienestar (EB) en Argentina surge en la década de 1940, cuando la industrialización sustitutiva generalizo la relación salarial en forma semejante a los países centrales con su modelo industrializador en la etapa justicialista primero y posteriormente en la etapa desarrollista (1958-1972) posibilitaron que el "Estado cumpliera una función reguladora de los intereses de las distintas clases sociales" (Torrado, 2004:18). 
es políticamente peligroso para el capitalismo" (Beccaria y Minujín, 1993:35).

En el escenario concreto que aquí se reconstruye, y sin ánimo de disminuir responsabilidades, el Gobierno de la Alianza formó parte de un momento histórico en el que diferentes gobiernos de América Latina pusieron en práctica el discurso de los organismos internacionales, a través de la implementación vernácula, por múltiples mecanismos, de los lineamientos de ajuste estructural ${ }^{6}$. En concordancia, se consolidó el proceso de reestructuración económica que afirma que el crecimiento económico se alcanza y sostiene con medidas ortodoxas resumidas en los principios establecidos por el Consenso de Washington ${ }^{7}$. Cabe señalar que los organismos internacionales de crédito que operaban en la región, como el Fondo Monetario Internacional y el Banco Mundial, formaban parte de los principales propulsores de los procesos políticos que reclamaban en asociación con los representantes locales de los intereses extranjeros en Argentina, la reforma estructural del Estado que consistía puntualmente en la implementación de los siguientes principios operativos: descentralización, privatizaciones de las empresas del Estado, desregulación del mercado, debilitamiento de las economías regionales y de las PyMEs y descrédito del sistema democrático representativo.

Como se ha señalado, el gobierno de entonces (la denominada Alianza De la Rúa - Álvarez, 1999-2001), siguiendo las recomendaciones de los organismos internacionales de crédito decidió profun-

\footnotetext{
6 Se define el ajuste estructural como "...la forma en que las economías nacionales deben adaptarse a las nuevas condiciones de la economía mundial" (Grassi, Hintze y Neufeld, 1994:24). Este ajuste, se basa en dos fórmulas: 1) abrir las economías nacionales al juego de las fuerzas del mercado mundial; y 2) minimizar el papel del Estado nacional como regulador de esas fuerzas y reducir su papel social y compensador. Ambas se expresaron por medio de los procesos de reforma del Estado durante los 90, que implicó las privatizaciones, la descentralización de las políticas sociales, la reforma tributaria y administrativa, la desregulación, el plan de convertibilidad, la reducción del déficit fiscal, y la flexibilización del mercado de trabajo.

7 Susana Hintze, socióloga argentina, recuerda los diez artículos que el economista John Williamson resume de dicho "Consenso". Los mismos fueron: 1) disciplina presupuestaria; 2) prioridad del gasto público en áreas que cuentan con elevados beneficios económicos y potencial para mejorar la distribución de la renta (asistencia médica primaria, educación e infraestructura); 3) reforma tributaria; 4) liberalización financiera; 5) tipos de cambio unificado; 6) liberalización comercial; 7) inversión directa extranjera basada en el principio de que las empresas extranjeras y nacionales compitan en términos de igualdad; 8) privatización de empresas públicas; 9) desregulación; 10) derechos de propiedad garantizados por el sistema legal (Alayón, 2010:277-285).
} 
dizar las políticas de ajuste. Una de las recomendaciones implementadas estuvo vinculada a la apropiación, por parte del Estado, de los ahorros de los sectores medios depositados en el sistema bancario que impedían el acceso a esos ahorros, constituyendo así lo que popularmente se llamó “el corralito". Por primera vez en la historia argentina, los trabajadores del Estado habían sido víctimas de una reducción salarial del 13\%, se les habían expropiado los ahorros y, en otros sectores de trabajo, se habían congelado los sueldos.

La impopularidad de estas medidas, sumada a la agudización del conflicto social, tornó inviable el modelo de convertibilidad sostenido hasta entonces, que establecía principalmente la paridad cambiaria de "un peso igual a un dólar". Las manifestaciones de ese malestar fueron masivas y se expresaron a través de cacerolazos, piquetes, huelgas y asambleas, donde nuevamente el Estado mostró su faz represiva frente a los reclamos de los sectores populares. Era necesario encontrar una salida a la crisis social económica financiera pero, fundamentalmente, era necesario comenzar a visibilizar la crisis político institucional más importante que atravesó al país que, encarnada en la consigna "que se vayan todos", licuaba la poca representación y legitimidad política y social que tenían los dirigentes. Tanto la política como las formas más tradicionales de representación y de agremiación de intereses estaban impugnadas. Se cuestionaba no sólo el modelo económico sino la misma forma democrática representativa de gobierno.

La crisis del 2001-2003 en la Argentina constituyó, entonces, la mayor manifestación social y política del agotamiento del Estado de Bienestar Argentino y del proyecto de desarrollo nacional y popular, cuya interrupción y desarticulación se inicia con diversos golpes militares, se profundiza con la última dictadura cívico-militar (19761983), cediendo paso a la implementación del modelo aperturista en democracia (Torrado, 2004) que posibilitó la instalación de un sistema especulador y liberal en lo económico; represivo y conservador en lo político. Así, la renuncia anticipada del entonces presidente De la Rúa, abrió un horizonte sin certeza que fue desde el 2001 al 2003. En este año, el 25 de Mayo y en una democracia debilitada, impugnada y 
sospechada, asumió democráticamente como Presidente electo el Dr. Néstor Kirchner con un frágil 22\% de los votos.

\section{Nadar contra la corriente}

En un escenario aún turbulento y de alta conflictividad social, caracterizado por la recesión, el desequilibrio estructural en su balance de divisas y un alto endeudamiento externo, operó en Argentina el denominado default.

La salida de la convertibilidad, a través de la devaluación, propició una serie de cambios macroeconómicos, sociales y políticos que favorecieron la inauguración de un nuevo ciclo denominado "nacionalpopular y democrático" $(2003-2013)^{8}$. En este ciclo se recuperó el trabajo, la educación, la innovación tecnológica, como estrategias de inclusión social, ampliando y universalizando derechos sociales con una clara orientación a la justicia distributiva posibilitando, así, que Argentina empezara a nadar contra la corriente, desobedeciendo las recomendaciones de los organismos internacionales de crédito, tan escuchadas hasta entonces.

En este sentido, Alicia Barcena, Secretaria Ejecutiva de la CEPAL afirma que "a partir de 2003, Argentina inició un cambio muy positivo. Hubo una acción muy valiente del Estado para transformar profundamente el modelo. Hay un quiebre cuando uno compara la década de los 90. Argentina junto con Brasil, Bolivia y Venezuela, son los países de la región que más redujeron la desigualdad y la pobreza. Eso sin contemplar la Asignación Universal por hijo; midiendo eso los resultados son todavía mejores. También ha mejorado considerablemente el balance de pagos y la cuenta corriente, la deuda pública tiene un muy buen comportamiento y aumentan las reservas interna-

8 Este nuevo ciclo que inicia con el gobierno del Dr. Néstor Kirchner (2003-2005) tuvo una etapa de reparación (recuperación económica con empleo e inclusión, 2003-2008), un punto de inflexión en el año 2008 y un nuevo periodo signado por la tensión política creciente, donde la disputa por la consolidación/ profundización de ese proyecto permanece abierta (Madoery, 2013:19). 
cionales. El Estado ha tomado decisiones correctas para la sociedad argentina (Barcena, 2010:24).

Dentro de estas decisiones se puede mencionar la definición de un nuevo tipo de cambio, el fomento del desarrollo de una industrialización nacional incipiente, la finalización de la sobrevaluación cambiaria, la nacionalización de los servicios públicos y la consolidación de un piso mínimo de ingreso monetario en los sectores populares a partir del aumento periódico del salario mínimo en el marco de acuerdos paritarios, del mejoramiento del ingreso de jubilaciones y pensiones con ajustes periódicos, de acuerdos de precios para limitar los procesos inflacionarios (Varesi, 2010:149). Se consiguió alejar al país de la cesación de pagos, se disminuyeron los índices de pobreza y de desempleo $^{9}$ y se produjo la cancelación anticipada de la totalidad de la deuda con el FMI por un monto de 9.810 millones de dólares, con el objetivo declarado de terminar con la sujeción de la política económica a las indicaciones de éste organismo internacional. Durante el año 2005, se realizó el canje de la deuda, que iniciaba las renegociaciones por los bonos que habían quedado en default desde 2001.

En contraposición a la concentración económica del ciclo neoliberal, las medidas tomadas en esta "etapa reparadora" (Madoery, 2013) de la post-convertibilidad ${ }^{10}$, se establecieron relaciones diferentes entre la sociedad, el Estado y el mercado, que permitieron la

9 Sólo a modo de ejemplo ya que no constituye el objetivo de este trabajo se presentan los siguientes datos estadísticos que dan cuenta de la magnitud del cambio social en el ciclo nacional-popular y democrático "...durante seis años a una tasa promedio de $8,6 \%$, la tasa de inversión subió del 11 al $23 \%$ entre 2002 y 2008 ; de 2001 a 2008 las exportaciones aumentaron de 26.500 a 70.000 millones de dólares. Con este telón de fondo de auge macroeconómico, comenzó a recuperarse el Estado de Bienestar, y cuando estalló la crisis internacional, la respuesta no fue desmantelar los avances logrados, sino profundizarlos: se defendió el empleo y se aumentó el gasto social, lo cual aceleró la salida de la recesión (...) se generaron 5 millones de nuevos empleos; se incorporó a 2,4 millones de nuevos jubilados, se recuperó para el Estado el sistema de Jubilaciones y se estableció un sistema automático de suba de montos; en el 2002 la participación de los salarios en el PIB era del 34\% y en el 2009 del 43\%, la desocupación cayó del 19,7\% en 2002 a 7,4\% en 2010,se implementó la asignación universal por hijo; se cumplieron importantes planes de vivienda y de salud; se ejecutan múltiples programas de desarrollo social ..." (Calcagno, 2011:46).

10 El nuevo escenario macroeconómico al que asiste la economía argentina desde principios de 2002, a partir del abandono de la paridad cambiaria fija, la consiguiente devaluación de la moneda y la liberalización del mercado de cambio permitirían prever una marcada intensificación de ese dinamismo exportador, más aún cuando a cuatro meses de abandono de la convertibilidad el proceso alcanzó el carácter de maxidevaluación $(200 \%$ de incremento del tipo de cambio, porcentual que al quinto mes se elevó al 250\% para luego estabilizarse en torno al 200\%) (Azpiazu y Basualdo, 2003:2). 
generación de un entramado social compuesto por cuenta propistas, microempresas, las cooperativas, las mutuales, las fábricas recuperadas, feriantes, ubicados en la interface entre la sociedad y el mercado (economía social ${ }^{11}$ ), que con la post-convertibilidad encontraron las condiciones propicias (tipo de política cambiaria, proceso de sustitución de las importaciones, Ley 26.355 de Marcas Colectivas, Ley 26.117 de Promoción del Microcrédito, Ley 25.865 de Monotributo Social, etc.) para su crecimiento y desarrollo. El Estado reconoció, registró y acompañó el proceso de institucionalización de los que se quedaron por fuera de las relaciones salariales, de la protección social, pero que trabajaban y producían...

Así, se reconoció a la economía social, configurándose un marco normativo y de políticas sociales que generan instrumentos para la articulación con sectores más estructurados de la economía promoviendo diferentes relaciones de asociatividad, tanto verticales como horizontales, entre el Estado y empresas que facilitan la acumulación de valor agregado y permiten la apertura y consolidación de la industria nacional en el mercado local y regional.

En este nadar a contra corriente, el ex Pte. Néstor Kirchner en el ejercicio de su gobierno, tomó algunas medidas políticas que, en un inicio, fueron consideradas como coyunturales de carácter transitorio pero que, con el paso del tiempo, en la continuidad del proyecto nacional y popular, fueron adquiriendo una dimensión y relevancia que hicieron de las mismas el eje político de ese nuevo ciclo. En este sentido, cabe mencionar algunos hitos centrales de la política argentina de este período:

- Ante todo, la instalación de la política por sobre lo político (Mouffe, 2006) ${ }^{12}$, que permitió entender que la riqueza no se distribu-

11 En este texto se utilizara indistintamente economía social, economía popular y economía solidaria. Cabe aclarar que esta última es un "concepto que abarca un amplio espectro de propuestas y expectativas, y debe permanecer plural, permitiendo la experimentación responsable en la búsqueda de nuevas formas de organización de la producción y la reproducción. Esas propuestas deben poder manifestar sus pretensiones de legitimidad y tendrán variadas respuestas en diversas culturas y situaciones históricas" (Coraggio, 2002).

12 Chantal Mouffe plantea la diferencia entre "la política" y "lo político" entendiendo a la primera como el conjunto de prácticas e instituciones a través de las cuales se crea un determinado orden, organizando la coexistencia humana en el contexto de la conflictividad derivada de lo político. Esto significa que la política es "un resultado", pero no exclusivo de las decisiones de los gobernantes 
ye naturalmente, sino que la misma se encuentra en litigio, en disputa y que es el Estado el que debe intervenir en el comportamiento de los sectores económicos dominantes con el objetivo de viabilizar la redistribución social del ingreso, en especial hacia los sectores populares.

- La anulación de las leyes de Obediencia Debida y Punto Final y el inicio del proceso de enjuiciamiento y condena efectiva a la violación de los Derechos Humanos por Delitos de Lesa Humanidad por parte de la Justicia Ordinaria.

- El establecimiento del enfoque de Derechos Humanos de manera transversal en todas las leyes sancionadas por el Congreso de la Nación y en el diseño e implementación de políticas sociales, fortalecieron procesos organizativos en los sectores populares permitiendo la democratización en la toma de decisiones, la apertura de nuevas instancias de debate y participación en la distribución por los espacios de poder.

- La intervención pública del Estado en la economía a fin de poder desarrollar una política de ingresos que contemple no sólo la gestión de los salarios sino también la gestión de los precios. En una economía recalentada por el aumento del consumo en el mercado interno de los sectores populares, la recomendación de los organismos internacionales y/o de sus representantes de enfriar la economía a partir de restringir el consumo de los pobres no constituye una solución posible dentro del modelo económico heterodoxo argentino (Zaiat, 2012:11) ${ }^{13}$. En este sentido, en materia de distribución del ingreso, se observaron cambios favorables hacia una menor concentración, debido sobre todo a un mejor reparto de los ingresos laborales y al papel redistributivo del Estado a través de las transferencias monetarias.

de turno. Chantal Mouffe también explica que en una democracia pluralista los sectores sociales enfrentados, en conflicto, deberían poder: reconocer la legitimidad de las demandas del oponente y reconocerse en un espacio simbólico común. Esto es a lo que la autora refiere como "relaciones agonistas". En una sociedad democrática liberal pluralista no se niega la existencia de los conflictos, sino que se proporcionan las instituciones que les permiten ser expresarlos.

13 El modelo económico heterodoxo argentino se construye en oposición y litigio con la ortodoxia económica "que concibe el orden natural en el mercado libre" (Zaiat, 2012:11). 
En relación a las políticas sociales, la revisión del discurso gubernamental en esta etapa, plantea la necesidad de distanciarse -no sólo discursivamente sino también desde las acciones- de las políticas sociales implementadas durante el período anterior. Hintze (2006) sostiene que la diferenciación entre estas políticas sociales y las del ciclo neoliberal se manifiesta a través de la enunciación que refiere al discurso gubernamental acerca de la necesidad "desde un estado en movimiento, con el centro puesto en la persona, no como un individuo aislado, sino como colectivos humanos y desde sus singularidades, atravesados por la trama social en la que están inmersos, buscando la construcción de un espacio inclusivo que fortalezca los derechos ciudadanos políticos, económicos, sociales, culturales y la equidad territorial" (Hintze, 2007:14).

Durante este ciclo nacional-popular y democrático, en esta "etapa reparadora”, al decir de Madoery (2013), que no estuvo ni está exenta de obstáculos, tensiones, disputas y conflictos, se propusieron y consolidaron las bases políticas, macroeconómicas y jurídicas de un Modelo de Desarrollo que interpeló e interpela al modelo de acumulación vigente permitiendo, desde los espacios intersticiales que posee todo sistema, la conformación del denominado Modelo $^{14}$ de Desarrollo Argentino (MDA).

Las políticas sociales del MDA, desde el Ministerio de Desarrollo Social de la Nación, estuvieron y aún permanecen centradas en los derechos humanos, en la inclusión social y en el Estado como parte principal de la dimensión social del desarrollo. Desde las mismas se prioriza la equiparación de oportunidades que generen cohesión social, proponiendo la reducción de la pobreza a través del restablecimiento del acceso al trabajo digno en el marco de los Convenios Colectivos de Trabajo, los Acuerdos Paritarios y del Consejo del Salario ${ }^{15}$. Las mis-

14 En relación a la noción de modelo se sigue la posición de Weber, entendiendo al mismo como un tipo ideal, como una construcción efectuada por el investigador que resume las principales características necesarias para investigar un fenómeno social. De este modo “...los tipos ideales se elaboran mediante la "acentuación unilateral de uno o algunos puntos de vista y mediante la reunión de gran cantidad de fenómenos concretos individuales existentes de un modo difuso (...) De este modo, son esquemas de interpretación, en tanto instrumentos de conocimiento y análisis” (Carballeda, 2002:24).

15 Ámbito institucional de carácter tripartito donde se reúnen periódicamente los representantes del gobierno nacional, de los trabajadores sindicalizados y de los empresarios con el fin de redistribuir el ingreso, acordar la asistencia a los desempleados y generar trabajo digno. 
mas se operativizan, en esta etapa, a través de la formulación de tres Planes Nacionales ${ }^{16}$ en búsqueda de la integralidad perdida en el ciclo neoliberal, contribuyendo así a la generación de las transformaciones sociales más importantes y profundas de los últimos treinta años en Argentina.

\section{El Modelo de Desarrollo Argentino (MDA)}

De esta forma, el Modelo de Desarrollo Argentino (MDA) ${ }^{17}$ al que se hace referencia en este artículo, no forma parte de un programa pre establecido, definido y publicado como tal. Se funda en un proyecto político nacional y popular que resiste a los embates y la voracidad del capitalismo transnacional y que se construyó desde los discursos y decisiones políticas del ex Pte. Néstor Kirchner, desde las políticas socia-

16 "Se presenta a continuación un resumen de las Políticas nacionales del Ministerio de Desarrollo Social de la Nación: a.- Plan "Familias por la inclusión social" consiste en la transferencia de ingresos a las familias pobres sin las contraprestaciones que exigía el Programa PJJHD. El monto de ingreso varía en función de la cantidad de hijos y demanda el compromiso del núcleo familiar con la educación y la salud de los menores a cargo. A la vez, contempla el ingreso en función de la cantidad de hijos a cargo, no exige la contraprestación laboral y es compatible con la posibilidad de contar con un trabajo registrado en el INJSP, mientras que la suma entre el plan familias y el trabajo formal no supere el monto del salario mínimo, vital y móvil. Contempla para su implementación de la puesta en marcha en territorio de diferentes dispositivos vinculados a la realización de talleres de desarrollo familiar y comunitario que buscan mejorar la posición de los adultos y jóvenes del núcleo familiar frente a situaciones que generan exclusión social. Se proponen así actividades vinculadas al desarrollo personal, familiar y comunitario y que facilitan el pleno acceso a servicios sociales y el goce de sus derechos de ciudadanía. b.- Plan Nacional de Seguridad Alimentaria "El Hambre más Urgente" garantiza la seguridad alimentaria para población vulnerable socialmente. c.- Plan de Desarrollo Local y Economía Social "Manos a la Obra": promueve la inclusión social a través de la generación de empleo y de participación en espacios comunitarios desde la convocatoria y organización de emprendimientos asociativos familiares, comunitarios y desde una línea que promueve el cooperativismo y el mutualismo dentro de los sectores de la economía social.

17 A continuación se incluye parte de un discurso brindado por el ex presidente Néstor Kirchner, en la ceremonia de clausura del $53^{\circ}$ en la Convención anual de la Cámara Argentina de la Construcción; desarrollada el 22 de noviembre de 2005 en Capital Federal, Argentina; seleccionado a los efectos de profundizar las características que venimos señalando: "Un modelo argentino de desarrollo, con consenso social e intersectorial, que se caracterice por el crecimiento con inclusión social, la defensa de los derechos más elementales del ser humano, la ubicación de los intereses de la Patria por encima de cualquier interés sectorial o corporativo, avanzando en la integración regional y en la integración al mundo. Un modelo argentino que ponga el acento en una distribución más equitativa del ingreso, que utilice intensivamente la inteligencia, el conocimiento, la capacidad de trabajo de nuestra gente, agregando calidad y valor a nuestra producción, favoreciendo la articulación y complementación entre los sectores públicos y privados. Un modelo con nuevo paradigma donde crear trabajo y ganar dinero en forma honesta, tenga reconocimiento social. Un modelo con empresas que asuman su responsabilidad social, teniendo presente el interés de sus trabajadores, de sus familias, del entorno social y ambiental de las zonas donde se localizan y de la sociedad en general". 
les, los aportes reflexivos de quienes formamos parte de una academia en diálogo con la sociedad, de los aportes de la militancia política y de las luchas reivindicativas de los sectores populares por el derecho a una vida más digna.

Partimos de afirmar que la realidad social, política y económica en Argentina es diferente a la del ciclo neoliberal. Lo expuesto hasta aquí propone ver que el MDA no constituye un punto de llegada sino el punto de partida para el desenvolvimiento de un proyecto situado sociopolítica y económicamente en un territorio que dialoga con el escenario internacional, regional, nacional y local. En este sentido, en coincidencia con lo expresado por Schunk y Rodríguez nos encontramos frente a un "histórico proceso de crecimiento actual que permite afirmar que estamos asistiendo la formación de un nuevo régimen de acumulación y desarrollo en la Argentina [cuyo] factor dinámico parece configurarse como una combinación entre un mercado interno sólido y expansivo, apuntalado por el aumento de la ocupación, los salarios, el gasto público, y una demanda externa de bienes de base primaria pero con creciente componente de valor agregado. En este régimen de acumulación, el crecimiento y la inversión se financian fundamentalmente con ahorro interno y el Estado asume un rol activo, aplicando políticas que promueven el crecimiento sostenido y la estabilidad económica, crean la infraestructura básica y aseguran la necesaria cohesión social” (Schunk y Rodríguez, 2011:19).

Aparece así la propuesta de un modelo que sintetiza las transformaciones sociales, políticas y económicas de este ciclo nacional-popular y democrático (Madoery, 2013) que, aunque ha vertebrado la política argentina del gobierno de Néstor Kirchner y su continuidad, se encuentra aún en debate y construcción, debiendo revalidarse de manera permanente, a través de elecciones democráticas que afiancen y profundicen los logros obtenidos: crecimiento sostenido, fortalecimiento del mercado interno, creación de trabajo digno y participación del Estado en la economía a favor de los sectores populares.

Por otra parte, cabe señalar que el MDA realizó una fuerte apuesta a la consolidación de una burguesía nacional, con una clara orientación "estado-céntrica", capaz de dirigir "la industrialización de 
la estructura económica, la democratización y modernización de la sociedad, tanto a partir de impulsos exógenos al territorio nacional (a través de la ayuda al desarrollo proveniente de los organismos internacionales) o exógenos a las regiones interiores de un Estado (a través de la planificación centralizada o la reasignación territorial de recursos)" (Madoery, 2008:16).

Por otra parte, es necesario aclarar que la territorialidad desde la que se piensa el MDA es diferente a la concepción del desarrollo sostenida desde una visión de lo local circunscripta al espacio físico geográfico, donde cada territorio en forma autónoma puede desarrollarse por sí mismo a partir de la movilización multiactoral y la definición de los problemas de abajo hacia arriba. Tal vez una de las mayores fortalezas del MDA es que concibe al desarrollo local, al "territorio" local, como parte de un territorio mayor de un proyecto de desarrollo nacional que no puede ser imaginado si no es desde la integración local-nacional-regional.

En algún sentido, el MDA presenta varios puntos en común con el modelo de desarrollo autosustentado (Cardoso y Faletto, 2003), a partir de reconocer principalmente la necesidad de generar un proceso de sustitución de las importaciones, de fortalecimiento de un sector industrial que produzca valor agregado a partir de la manufactura y/o industrialización de materias primas, de priorizar el mercado y el consumo interno y fundamentalmente de socializar la renta. Este último punto constituye una novedad respecto a los planteos del ciclo neoliberal, ya que el MDA propone un modelo de desarrollo de "derrame inducido" hacia los sectores populares. Como bien señala Eduardo Devés Valdez, "esta teoría del desarrollo debe explicar, en una perspectiva macroeconómica, las causas y el mecanismo de aumentos persistentes de la producción y la forma en la que se distribuye y utiliza el producto social. Este proceso que es el desarrollo económico 'constituye un fenómeno de evidente dimensión histórica'. Una teoría del desarrollo tiene entonces como problema central el aumento de la productividad del trabajo y sus repercusiones en la distribución y utilización del producto social” (2003:13-18). 
El problema del desarrollo, entonces, constituye el núcleo central del MDA. Conceptualmente se considera que si bien este problema debe ser abordado desde las teorías heterodoxas de la economía, a partir de tres núcleos principales de pensamiento provenientes del Plan Fénix, del Cepalismo de larga tradición Latinoamericana, en especial de los aportes que efectúa el Dr. Aldo Ferrer y del Centro de Estudios para el Desarrollo Argentino (CENDA); esto no resulta por sí suficiente si no se reconoce también la complejidad que implica abordar el campo del desarrollo del subdesarrollo, a contra mano de la tradición ortodoxa de la economía. Roig (2008) considera que esta complejidad se da no sólo por el carácter polisémico y la pluralidad de usos académicos que posee de la categoría desarrollo o por la contradicción de definiciones que existentes, sino que está dada principalmente en los diferentes usos políticos que se efectúa de la categoría. El autor plantea que para reactualizar el debate en torno al desarrollo es necesario distinguir no sólo entre los modos y los modelos de desarrollo ${ }^{18}$ sino también acerca de la manera en que históricamente se impusieron en pugna los diferentes significados sobre lo que era desarrollarse (Roig, 2008:82).

Complementariamente a lo antes planteado, se suma la perspectiva ya citada de Madoery (2013) que enfatiza la dimensión política del desarrollo, entendiendo que para las sociedades latinoamericanas la presencia o ausencia de desarrollo no constituye un problema neutral, susceptible de ser intervenido desde la mera gestión técnica, sino que debe ser comprendido y abordado como un problema político que debe no sólo habilitar un debate plural sino también una instancia de construcción colectiva.

En este debate, que consideramos central, quizás sirva preguntarse con Alcira Argumedo acerca de "¿Dónde se decide el modelo de de-

18 Se entiende por modos de desarrollo "....al proceso de transformación de las instituciones que surgen de la dinámica de los conflictos estructurales. Cada modo de desarrollo es singular ya que los conflictos estructurales se expresan históricamente en forma singular en cada ámbito nacional. No hay teleología en el modo de desarrollo aunque si lo hay en un modelo de desarrollo" mientras que los modelos de desarrollo hacen referencia a "...una forma idealizada y orientada hacia el futuro de lo que se quiere y se desea. El modelo de desarrollo no es un proceso histórico...es un programa de acción en devenir, es el desarrollo en su dimensión transitiva. Cualquier modelo de desarrollo es eminentemente político" (Roig, 2008:88). 
sarrollo, de progreso? ¿Quiénes generan la cultura del proyecto? ¿Los economistas? ¿Los planificadores? ¿Es seguro que se debe recibir desde las clases populares y devolverles una problemática que, a su vez sufre los efectos de una brutal desinformación colectiva? ${ }^{19}$ Es preguntarse acerca del potencial contenido en la capacidad participativa, de las formas de gestación de hegemonía para un proyecto democrático, asentado en la creatividad de capas sociales actualmente condenadas por las políticas de modernización salvaje” (1993:240).

Estos interrogantes refuerzan la idea de que profundizar acerca de los alcances, limitaciones, deudas y desafíos que plantea el problema del desarrollo en el MDA implica habilitar otras tradiciones conceptuales que no reduzcan la diversidad y complejidad de nuestras sociedades al binomio desarrollo/sub desarrollo y que posibiliten la formulación de una propuesta de desarrollo con crecimiento económico e inclusión social que habilite el reconocimiento a otras formas de institucionalidad, de organización del territorio, de vínculos sociales, prácticas culturales, modos de ver y entender la vida pre existentes al modelo agro exportador (Torrado, 2004) sobre el que se fundó el Estado-Nación Argentino.

En este sentido, sostenemos que el MDA constituye una invitación a pensar situadamente la realidad económica, social y política de América Latina y de Argentina en particular y que a pesar de los grandes esfuerzos realizados, el MDA aun presenta una serie de deudas vinculadas a la generación de trabajo con protección social para aquellos trabajadores de la economía popular así como la construcción de relaciones diferentes con la naturaleza que no queden resumidas a una posición extractivista y poco sustentable de los recursos naturales.

19 Ford (1987). 


\section{Pensar desde otro lugar}

Como hemos visto, el abordaje del problema del desarrollo desde el análisis del caso argentino del primer gobierno kirchnerista, nos pone también ante un problema de la determinación de categorías conceptuales y, al mismo tiempo, de los marcos de pensamiento que dan origen a la comprensión de esas categorías. El MDA, como toda novedad significativa en un plano político de la dimensión de la praxis, requiere de la construcción de un espacio epistémico, de reflexión y diálogo teórico-político que promueva el debate acerca del desarrollo en América Latina en general y Argentina en particular. El punto nodal de este debate no será otro que el de la interpelación de la influencia y pregnancia de la racionalidad moderna/occidental en nuestras vidas, en nuestra manera de ser y pensar, en los modos de concebir la ciencia y la tecnología, el trabajo, la educación, la cultura.

A partir de lo propuesto por Cristóbal Kay, en su texto "Teorías latinoamericanas del desarrollo", se pueden abordar los aspectos conceptuales de la teoría del desarrollo desde la identificación de las diferentes contribuciones efectuadas en América Latina, a partir de los siguientes enfoques que contribuyen a descolonizar la categoría de desarrollo, desde un pensar situado que interpele la matriz capitalista/patriarcal, cristiana/occidental, moderna, colonial y eurocentrada (Grosfoguel, 2006:23). Dentro de estos aportes, entonces, se reconocen los siguientes enfoques:

a. La perspectiva estructuralista y la teoría del centro-periferia de Raúl Prebisch y, posteriormente, las producciones de la CEPAL.

b.. La mirada del colonialismo interno, cuyos principales referentes durante la década de los 60 fueron Pablo González Casanova y Rodolfo Stavenhagen, y que introdujeron el concepto de etnia, interpelando la clásica categoría marxista de relaciones de clases.

c. El enfoque de la marginalidad, representado en la década de los 60 por Gino Germani, exponente de la teoría de la modernización de América Latina y, desde el enfoque marxista, a través de los aportes efectuados por Aníbal Quijano, que entiende que el enfoque 
de la marginalidad refleja una manera particular de integración y participación y Nun, que crea la novedosa categoría de "masa marginal" diferenciándola de los conceptos marxistas de "sobrepoblación relativa" y "ejército de reserva".

d. El de la dependencia en sus dos variantes: la reformista, representada por Fernando Henrique Cardozo, Osvaldo Sunkel, Celso Furtado, Helio Jaguaribe, Aldo Ferrer y Aníbal Pinto; y la perspectiva neo marxista, representada por Theodonio dos Santos, André Gunder Frank, Aníbal Quijano, Oscar Braun, entre otros.

Retomar estas tradiciones requiere revisar no sólo cómo se han establecido históricamente las relaciones de poder en la producción del conocimiento y pensamiento entre Europa y América Latina, tanto en torno a la producción y reproducción de la pobreza como a las propuestas de desarrollo para nuestros países, sino también un esfuerzo mayor de despojarnos de un pensamiento único y ortodoxo para contribuir, desde el pensamiento crítico latinoamericano, a la construcción de propuestas políticas y epistémicas contestatarias o transgresoras de la matriz argumentativa de la modernidad/colonialidad.

Desde esa perspectiva, el desarrollo no sólo constituye un proceso social que conlleva en sí cierta dimensión utópica de una sociedad diferente, mejor, deseable, sino que además configura un concepto con implicaciones socioeconómicas, ambientales, políticas y culturales en las cuales subyacen lecturas intencionadas y fundamentos filosóficos, epistemológicos, éticos, que afectan la vida cotidiana de nuestros pueblos. Esta búsqueda permite ir tras la síntesis y la articulación de las reflexiones, así como enriquecer y profundizar, simultáneamente, las múltiples dimensiones de la vida social.

Podemos reunir varias de nuestra reflexiones al decir que si bien desde los países centrales se impulsó un modelo de desarrollo que se encuentra vinculado fuertemente a un modelo de racionalidad científica por encima de otros saberes y prácticas societales, asimilando la idea de desarrollo a la de progreso y, fundamentalmente, a una única forma de ordenamiento social y económico; abordar el uso de esta categoría para el caso de América Latina requiere una consideración 
diferencial. Repensar e interpretar de manera crítica las concepciones de desarrollo en el marco del MDA constituye un reto epistemológico y político que posibilita explicitar las intencionalidades, ideologías y posturas epistemológicas que abonan a la constitución del pensamiento la praxis social.

América Latina se presenta, entonces, desde esta perspectiva, como una zona de refugio de lo diferente, un espacio de invención y de resignificación de lo instituido, tendiente a sostener la presencia de los Estados Nacionales, la democracia como forma de gobierno y de la organización del poder a través de la República.

Es desde Nuestra América que se han llevado acciones tanto en el plano político, económico, cultural y social que ponen en valor las capacidades, potencialidades y recursos existentes para establecer, en un esquema productivo de sustitución de las importaciones, fuertes alianzas y articulaciones dentro de lo que se denomina "cooperación Sur-Sur". Paralelamente al proceso que hemos comentado, en otros países de América Latina comenzó y se fue afianzando un ciclo económico y político a contramano de las recomendaciones y medidas que rigieron con fuerza en la región en los 90 por parte de los organismos financieros internacionales, principalmente el FMI y el Banco Mundial.

Parte de este cambio es la consolidación de gobiernos democráticos en toda la región, ya sean los autodenominados socialistas (como es el caso de Venezuela, Bolivia, Ecuador), o que se reconozcan construyendo desde el capitalismo nacional (Argentina y Brasil), como una alternativa complementaria a la economía capitalista del libre mercado.

Néstor Kirchner impulsó y formó parte de un grupo de mandatarios de varios países latinoamericanos que, junto con Hugo Chávez (Venezuela) y Lula Da Silva (Brasil), lideraron en el año 2005 la IV Cumbre de las Américas, realizada en la ciudad de Mar del Plata, en la que el gobierno expresó, con el apoyo de otros gobiernos latinoamericanos -Tabaré Vázquez (Uruguay), Evo Morales (Bolivia), Michelle Bachelet (Chile), Rafael Correa (Ecuador)- la oposición a la firma del Área de Libre Comercio de las Américas (ALCA), impulsa- 
da por Estados Unidos y obtuvo, por otra parte, la constitución de un espacio político de integración regional de tendencias no-neoliberales.

Desde estas dos vertientes, estos países acuerdan acerca de la necesidad de dar centralidad al Estado y conformar espacios de integración regional, tales como el Mercosur, la Celac y la Unión de Naciones Sudamericanas (UNaSur), como forma efectiva de enfrentar los embates de los sectores concentrados de la economía.

\section{Para seguir discutiendo}

A partir del caso argentino expuesto y de los correlatos que pueden observarse en otros países de América Latina, es posible evidenciar la resistencia de esta porción de globo para priorizar la defensa de los derechos humanos, del derecho internacional, del derecho de los pueblos; desde la defensa del sistema democrático como sistema de gobierno y de vida, a los embates sistemáticos del neoliberalismo globalizado y de los representantes vernáculos de esos intereses en nuestros países.

Avanzar en este proceso reflexivo, desde una posición histórica acerca de lo ocurrido y de lo que nos ocurre, presenta al menos un inconveniente: el de intentar deliberar desde la proximidad biográfica de los hechos contemporáneos, que nos encuentran como testigos y protagonistas de los mismos. Es tal vez desde esta complejidad que se constituye una de las diferentes maneras de abordar este debate: reconocer el carácter sincrónico que van adquiriendo las diferentes luchas populares en su búsqueda por constituir una América Latina libre, justa y soberana. Por otra parte, este esfuerzo nos permite pensar una América Latina que deje de ser el laboratorio donde el neoliberalismo experimenta sus "nuevas" recetas para profundizar la desigualdad y se constituya activamente en esa zona de refugio, de protección, de las iniciativas populares emancipadoras.

El nuevo consenso generado desde los países de América Latina que integraron la negativa al ALCA, no surge de un enfoque renovado en términos de una visión amplia en torno a los derechos hu- 
manos, sino de la búsqueda de nuevos elementos superadores ante el evidente fracaso de las políticas focalizadas de las décadas de los $80 \mathrm{y}$ los 90, promovidas particularmente por los organismos de asistencia crediticia. Esto permite, entre otras cuestiones, una valoración diferente del territorio nacional y de las alianzas que se efectúan tanto al interior del mismo como en diferentes estados. Estos espacios parten del reconocimiento de la soberanía de cada uno de los Estados miembros para generar alianzas en pos de enfrentar los embates de los sectores, grupos corporativos y países que pretenden desarrollar una política colonialista e imperialista en América Latina.

Así, cabe insistir en la fuerte impronta redistributiva de la renta que poseen los gobiernos que forman parte de estos espacios y que se materializó en la implementación de una serie de políticas sociales, modificando no sólo el discurso sino también la práctica de reparación por parte del Estado de las inequidades generadas por el mercado. Debe tenerse en cuenta que este tipo de políticas implica profundizar un debate sobre la justicia distributiva, la propiedad de los recursos y la concentración de capitales, así como también retomar la cuestión de la liberación como conquista de la libertad y autonomía de los pueblos de América Latina.

El MDA, como punto clave en la estructura social y política contemporánea, inició un período histórico de nuestro país -y acompañado en el contexto latinoamericano- signado por procesos sostenidos de cambios políticos, sociales, culturales y económicos que generaron las condiciones para el acceso de miles de argentinos/as al trabajo digno, a la educación, a la salud, a la seguridad social. Con esto inauguró una nueva agenda pública de debate político vinculada a la discusión de la redistribución de la renta, de las implicancias del desarrollo y nos invitó y nos invita a revisar desde dónde pensamos los parámetros y horizontes que direccionan el curso de las transformaciones sociales. 


\section{Referencias bibliográficas}

ARGUMEDO, A. Los silencios y las voces en América Latina: notas sobre el pensamiento nacional y popular. Buenos Aires, Editorial Colihue, 1993.

AZPIAZU, D. y BASUALDO, E. M. "Las exportaciones vitivinícolas durante la postconvertibilidad", en: Las exportaciones vitivinícolas durante la postconvertibilidad. Argentina, Facultad Latinoamericana de Ciencias Sociales (FLACSO), 2003. [En línea: 03/06/2014] Disponible en: http://bibliotecavirtual.clacso.org.ar/ar/libros/argentina flacso/no14AZPIAZUBASUALDOExportaciones.pdf.

BECCARIA, L. y LOPEZ, N. (comps). Sin Trabajo: Las características del desempleo y sus efectos en la sociedad argentina. Buenos Aires, UNICEF/Losada, 1997.

BECCARIA, L. "Empleo, remuneraciones y diferenciación social en el último cuarto del siglo XX", en: Sociedad y sociabilidad en la Argentina de los 90. Universidad Nacional de General Sarmiento. Buenos Aires, Biblos, 2002.

CAlCAGNO, E. y CALCAGNO, A.E. El Resurgimiento Argentino. Buenos Aires, Instituto de Estudios Políticos Facultad de Ciencias Sociales, UNLZ, 2011.

CARDOSO, F. H. y FALETTO, E. Dependencia y desarrollo en América Latina.

Ensayo de interpretación sociológica. México, Siglo XXI, 2003.

CARBALLEDA, A. La intervención en lo social. Exclusión e integración en los nuevos escenarios sociales. Buenos Aires, Paidós, 2002.

CEPAL y ONU. "Capítulo I. Pobreza, Desigualdad y Percepciones sobre el mundo del trabajo en América Latina”, en: Panorama Social de América Latina, CEPAL-ONU, 2011.

COMISIÓN DE ECONOMÍA DE CARTA ABIERTA. Primer Documento de Trabajo Colectivo: "Sin Estado no hay Nación”. Buenos Aires, 2008.

DEVÉS VALDÉS, E. El pensamiento latinoamericano en el siglo XX. Desde la CEPAL al neoliberalismo (1950-1990). Tomo II. Buenos Aires, Editorial Biblos, 2003.

GRASSI, E. "Prólogo", en: LAGUADO DUCA, A. La construcción de la cuestión social El desarrollismo post peronista. Buenos Aires, Editorial Espacio, 2011.

GROSFOGUEL, R. "La descolonización de la economía política y los estudios postcoloniales: transmodernidad, pensamiento fronterizo y colonialidad global", en: Revista Tabula Rasa. No 4, 2006. Pp. 17-48. [En línea: 15/09/2014] Disponible en: http:/] www.scielo.org.co/scielo.

KAY, C. “Teorías latinoamericanas del desarrollo”, en Revista Nueva Sociedad, N 113, mayo-junio 1991. pp. 101-113.

KIRCHNER, A. "La caracterización de las políticas”, 2007. [En línea: 16102014]. Disponible en http:/ $w$ ww.desarrollosocial.gov.an. 
KIRCHNER, A. "Políticas sociales integradas" en: HINTZE, S. Politicas sociales argentinas en el cambio de siglo. Conjeturas sobre lo posible. $1^{\circ}$ edición. Buenos Aires, Espacio, 2006.

KIRCHNER, A. Políticas Sociales del Bicentenario Un modelo Nacional y popular. Tomo I. Buenos Aires, Ministerio de Desarrollo Social de la Nación, 2010.

LUKIN, T. “'Argentina es uno de los países que más redujeron la desigualdad y la pobreza'”. Entrevista a Alicia Barcena, Secretaria Ejecutiva de la CEPAL. Suplemento de Economía Cash N ${ }^{\circ}$ 1081, Diario Página 12, 19 de diciembre 2010.

MADOERY, O. "El desarrollo como categoría política”, en: Revista Crítica y Emancipación, $\mathrm{N}^{\circ}$ 7. Buenos Aires, CLACSO, 2012. Pp. 59-83.

MADOERY, O. Otro Desarrollo. El cambio desde las ciudades y regiones. Buenos Aires, Editorial de la Universidad Nacional San Martín, 2008.

MADOERY, O. et. al. La democracia argentina como escenario de disputa hegemónica. Rosario, Editorial de la Universidad Nacional de Rosario, 2013.

MINUJIN, A. y BECCARIA, L. Desigualdad y exclusión. Desafíos para la politica social argentina de fin de siglo. Buenos Aires, UNICEF/Losada, 1997.

MOUFFE, C. En torno a lo político. Buenos Aires, Fondo de Cultura Económica, 2005.

NAHON, C., RODRIGUEZ ENRIQUEZ, C. SCHORR, M. "Crítica y teoría en el pensamiento social latinoamericano" en: El pensamiento latinoamericano en el campo del desarrollo del subdesarrollo: trayectoria, rupturas y continuidades, Buenos Aires, CLACSO, 2006. [En línea: 02/05/2014] Disponible en: http://biblioteca.clacso.edu.ar/ar] libros/becas/critica/critica.htm.

PRESBICH, R. "El desarrollo económico en América latina y algunos de sus principales problemas", en: Boletín Económico de América Latina. Vol. VII. Buenos Aires, 1962. Pp.1-24.

RODRÍGUEZ, L. Educación Popular en la historia reciente en Argentina y América Latina. Aportes para balance y prospectiva. Buenos Aires, APPEAL, 2013.

ROIG, A. "El desarrollo como conflicto institucionalizado", en: PÉREZ SOSTO, G. (coord.). El Estado y la reconfiguración de las protecciones sociales. Buenos Aires, Siglo XXI, 2008.

VARESI, G. "La Argentina posconvertibilidad: modelo de acumulación”, en: Problemas del Desarrollo, Revista Latinoamérica de Economía, UNAM, México, 2010. [En línea: 16/09/2014] Disponible en: http://www.revistas.unam.mx/index.php/pde/article/ view/18500

SCHUNK, R. y RODRIGUEZ, L. 2003 - 2010: La reconstrucción de un país. Economía política del peronismo kirchnerista. Santa Fe, Librería Cívica, 2011. 
YANNUZZI, M. A. "Estado y Sociedad Global”. Universidad Nacional de Rosario, 2010. Mimeo.

ZAIAT, A. Economía a contramano. Cómo entender la economía política. Buenos Aires, Editorial Planeta, 2012.

Recepción: 17/03/2015

Aceptación: 03/08/2015 